\title{
BMJ Open Long-term cost reduction of routine medications following a residential programme combining physical activity and nutrition in the treatment of type 2 diabetes: a prospective cohort study
}

Charlotte Lanhers, ${ }^{1}$ Guillaume Walther, ${ }^{2}$ Robert Chapier, ${ }^{3}$ Bruno Lesourd, ${ }^{3}$ Geraldine Naughton, ${ }^{4}$ Bruno Pereira, ${ }^{5}$ Martine Duclos, ${ }^{6}$ Agnès Vinet, ${ }^{2}$ Philippe Obert, ${ }^{2,4}$ Daniel Courteix, ${ }^{3,4}$ Frédéric Dutheil ${ }^{4,7}$

To cite: Lanhers $C$, Walther G, Chapier R, et al. Long-term cost reduction of routine medications following a residential programme combining physical activity and nutrition in the treatment of type 2 diabetes: a prospective cohort study. BMJ Open 2017;7:e013763. doi:10.1136/bmjopen-2016013763

- Prepublication history for this paper is available online. To view these files please visit the journal online (http://dx.doi.org/10.1136/ bmjopen-2016-013763).

Received 5 August 2016 Revised 2 February 2017 Accepted 7 February 2017

CrossMark

For numbered affiliations see end of article.

Correspondence to Dr Frédéric Dutheil; frederic.dutheil@acu.edu.au

\section{ABSTRACT}

Objectives: To demonstrate that lifestyle modifications will reduce the cost of routine medications in individuals with type 2 diabetes (T2D), through a mechanism involving glycaemic control.

Design: A within-trial cost-medication analysis with a 1-year time horizon.

Setting: Controlled environment within the spa resort of Chatel-Guyon, France.

Participants: Twenty-nine participants (aged 5070 years) with T2D.

Interventions: A 1-year follow-up intervention, beginning with a 3-week residential programme combining high exercise volume (15-20 hours/week), restrictive diet $(-500 \mathrm{kcal} /$ day $)$ and education. Participants continued their routine medication, independently managed by their general practitioner. Main outcome measures: Number of medications, number of pills, cost of medications and health-related outcomes.

Results: Twenty-six participants completed the 1-year intervention. At 1 year, 14 patients out of $26(54 \%)$ stopped/decreased their medications whereas only 5 $(19 \%)$ increased or introduced new drugs $\left(\chi^{2}=6.3\right.$, $p=0.02$ ). The number of pills per day decreased by 1.3 \pm 0.3 at 12 months $(p<0.001)$. The annual cost of medications for T2D were lower at 1 year $(€ 135.1$ $\pm 43.9)$ versus baseline $(€ 212.6 \pm 35.8)(p=0.03)$. The regression coefficients on costs of routine medication were $0.507(95 \% \mathrm{Cl} 0.056$ to $0.959, \mathrm{p}=0.027)$ for $\mathrm{HbA} 1 \mathrm{C}$ and $0.156(95 \% \mathrm{Cl}-0.010$ to $0.322, \mathrm{p}=0.06)$

for blood glucose levels. Diabetics patients with $\mathrm{HbA1c}$ $>6.5 \%$ in the highest (last) quartile doubled their routine medication costs ( $66 \%$ vs $33 \%, p=0.037$ ).

Conclusions: Individuals with T2D reduced routine medication costs following a long-term lifestyle intervention that started with a 3-week residential programme. Combining high exercise volume, restrictive diet and education effectively supported the health of T2D. The main factor explaining reduced medication costs was better glycaemic control,

\section{Strengths and limitations of this study}

- Reducing the long-term cost of global routine medication was effective following a lifestyle residential programme in type 2 diabetes (T2D) patients.

- Innovation also lies in high training volumes (15-20 hours/week) that have seldom been investigated in obesity intervention over 12 months.

- The main limitations are a small sample size of T2D patients and the absence of a control group.

- A group without physical activity could also have provided opportunities to distinguish the effects of physical activity from the diet.

independent of weight changes. Despite limitations precluding generalisability, cost-effective results of reduced medication should contribute to the evidence base required to promote lifestyle interventions for individuals with T2D.

Trial registration number: NCT00917917;

Post-results.

\section{BACKGROUND}

Type 2 diabetes mellitus (T2D) is a major health issue that is associated with considerable morbidity and mortality. ${ }^{1}$ Globally, the number of people with T2D is projected to increase to 366 million by $2030 .^{2}$ As many as one in three US adults could have T2D by 2050, if current trends continue. ${ }^{3}$

The costly and debilitating microvascular and macrovascular complications of poorly controlled diabetes include renal failure, visual impairment, lower limb amputation, heart disease and stroke. Therefore, intensive and sustained individual effort is required to 
achieve optimum control. ${ }^{4}$ T2D imposes a substantial burden on the economy worldwide in the form of increased medical costs and indirect costs from workrelated absenteeism, reduced productivity at work and at home, reduced labour force participation from chronic disability and premature mortality. ${ }^{5}$ In 2007 , the global health expenditure to treat and prevent T2D and its complications was estimated to be at least US\$232 billion, ${ }^{6}$ increasing dramatically in recent years. Depending on available treatments and local prevalence, the direct costs of T2D consume from $2.5 \%$ to $15.0 \%$ of annual healthcare budgets. ${ }^{7}$

T2D is a chronic illness requiring continuous medical care with multifactorial risk reduction strategies beyond glycaemic control. ${ }^{8}$ Inadequate glycaemic control is thought to be a cause of diabetic complications and higher costs. Appropriate management of diabetes can delay complications, reduce mortality and reduce the costs of diabetes care, particularly medical costs.

The latest recommendations from diabetes care in 2015 concluded that education for self-management is critical. ${ }^{8}$ Within the recommendations, adults with diabetes were advised to perform at least $150 \mathrm{~min} /$ week of moderate-intensity aerobic physical activity (at $50-70 \%$ of maximum heart rate), spread over at least 3 days/week with no more than 2 consecutive days without exercise. In the absence of contraindications, it was recommended that adults with T2D perform resistance training at least twice per week. Moreover, the integral role of nutrition therapy was emphasised, including a balance diet associated with reduction in excess body weight for overweight patients. However, although physical activity and nutrition represent a cornerstone for managing T2D, it is often difficult to incorporate regular physical activity into daily lives, in combination with healthy nutritional intake. To date, no study combining physical activity and nutrition has specifically investigated T2D medical costs before and after a 3-week residential programme with a long-term follow-up at 12 months. Moreover, no study has examined the relation between glycaemic control and medical costs after lifestyle modifications.

We hypothesised that (1) lifestyle modifications would reduce the costs of routine medications in T2D patients and (2) the glycaemic control would be a major factor explaining this reduction.

Therefore, we aimed to evaluate any reductions of routine medications in T2D patients after a lifestyle intervention. A secondary aim was to investigate the association between the cost of medications and clinical as well as biological parameters. This study is part of the larger REverse metabolic SyndrOme by Lifestyle and Various Exercises (RESOLVE) trial.

\section{METHODS}

Participants

Participants were recruited via advertisements. They provided written informed consent. Participants were eligible if they met the following criteria: being aged between 50 and 70 years, suffering from T2D, practicing $<3$ hours of physical activity per week, having a stable body weight, without changes in prescribed medications over the previous 6 months, and without hepatic, renal or psychiatric diseases. Potential participants also needed to be free from endocrine diseases, except the insulin-resistance defining T2D, and without medications known to alter body weight, nor having a history of restricted dieting in the previous year. Further, participants needed to complete a maximal exercise tolerance test that included continuous ECG monitoring, attesting to the absence of cardiovascular disease. For baseline comparisons, aged-matched healthy controls were recruited with no disease/medication and parameter of the metabolic syndrome, ${ }^{9}$ as metabolic syndrome is considered as a pre-diabetic stage. ${ }^{10}$

\section{First stage of intervention: a 3-week residential programme}

Participants attended lectures and educational workshops on T2D, nutrition, cooking and exercise including a strong focus on sustainable lifestyle changes. Throughout the residential programme, food intake and physical activity were continuously monitored to reach targets set by investigators. Nutritional intakes were assessed by dieticians. T2D participants underwent a daily diet restriction $(-500 \mathrm{kcal} /$ day) with protein accounting for $15-20 \%$ of the total energy intake $(1.2 \mathrm{~g} / \mathrm{kg} /$ day $)$, lipids $30-35 \%$ and carbohydrates the remainder. Basal metabolic rate (BMR) was calculated using the equations of Black. ${ }^{11}$ Participants were coached individually by physical education professionals. Participants had to exercise 1520 hours/week, using endurance training (90 min daily: aquagym, cycling or walking) and resistance training (90 $\mathrm{min} \times 4$ days a week). Resistance training consisted of eight exercises with free weights and traditional muscle building equipment. Sundays were dedicated to a wholeday trek. Heart rate was monitored by Polar S810 allowing to calculate the energy expenditure. ${ }^{12}$

\section{Second stage of intervention: a 1-year at-home follow-up}

Following the first stage of intervention (D20), T2D participants continued their lifestyle changes at home for 1 year. They were asked to maintain the lifestyle (diet and physical activity) changes experienced during the residential programme. Dietary and exercise practices during this period were assessed with the use of a compliance score determined on the basis of the number of food questionnaires returned and the number of training sessions undertaken per week. The overall compliance score was the mean of these two scores (nutrition and physical activity ${ }^{13}$ (figure 1 ).

\section{Primary outcomes: medications}

Participants were advised to continue their medication which was independently managed by their general practitioner. 


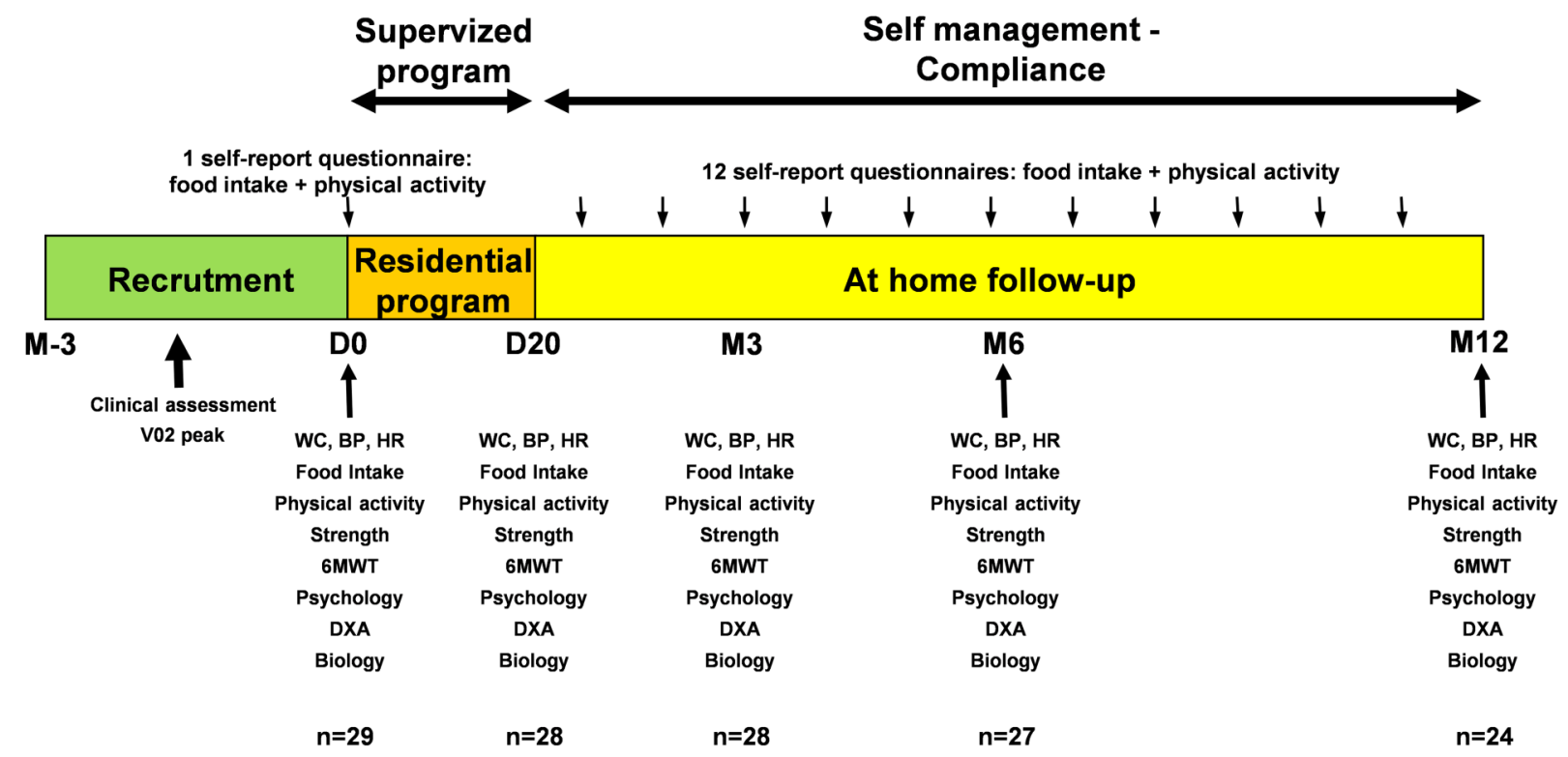

Figure 1 Study design: a 3-week residential programme with standardised and personalised diet and physical activity, and a 1-year at-home follow-up. 6MWT, 6 min walk test; BP, blood pressure; DXA, densitometry X-ray absorption; HR, heart rate; WC, waist circumference.

Routine medications and number of pills per day were recorded. Cost of treatment were calculated on the basis of the cost given by the dictionary of medications (Guide thérapeutique, Elsevier-Masson, 2014) for France, and on online sale of drugs (Rxusa, Pharmacychecker) for the USA. We multiplied the cost of one pill by the number of pills per day by 365 days to calculate the annual cost for each medication.

\section{Secondary outcomes}

Central fat, a surrogate of visceral fat, was assessed from dual-energy X-ray absorptiometry (DXA, Hologic QDR 4500 series; Waltham, USA), according to Kamel et al. ${ }^{14}$ Our laboratory reports in vivo coefficients of variation (CV) of $1.6 \%$ in central fat measures from 20 participants. The CV for total body mass was $4.2 \%$. Blood pressure and heart rate were measured after $15 \mathrm{~min}$ of rest, using an automated upper arm sphygmomanometer (SunTech Medical, Model 222).

Fasting blood samples were drawn between 7:00 and 7:30, aliquoted and stored at $-80^{\circ} \mathrm{C}$ until analyses. Basic biological assays were performed in the biochemistry laboratory of the University Hospital (Clermont-Ferrand, France). Insulin, pro-inflammatory cytokines (tumor necrosis factor (TNF- $\alpha$ ) and interleukin 6 (IL-6)), vascular endothelial growth factor (VEGF) and N-terminal pro-brain natriuretic peptide (NT-proBNP) were assayed by ELISA kits (Millipore, Billerica, Massachusetts, USA). Sensitivity, intra-assay and interassay $\mathrm{CV}$ were, respectively, $3.0 \mathrm{ng} / \mathrm{mL}, 2.6 \%, 7.2 \%$ for insulin, $0.7 \mathrm{pg} / \mathrm{mL}, 6.0 \%$ and $9.0 \%$, for TNF- $\alpha, 1.3 \mathrm{pg} /$ $\mathrm{mL}, 7.0 \%$ and $10.0 \%$ for IL-6, $5.9 \mathrm{pg} / \mathrm{mL}, 4.1 \%$ and $5.4 \%$ for VEGF.

Physical performance tests were conducted for strength and endurance. Specifically, strength was evaluated by summing the maximum load of 10 repetitions from three prescribed exercises (bench press, leg extension, biceps curl). ${ }^{13}$ Endurance was assessed by the 6 min walk test $(6 \mathrm{MWT}){ }^{15}$

\section{Time of measures}

Data were collected at baseline (day 0), 21 days (D20), 3 months (M3), 6 months (M6) and 12 months (M12).

\section{Statistical analysis}

Statistical analyses were performed using SPSS (v19, SPSS ., Chicago, Illinois, USA) and Stata software (v12, Stata-Corp, Texas, USA). Data are presented as mean \pm SD unless otherwise specified. Normality of distribution was assessed by the Shapiro-Wilk test. The primary focus of the analyses was the 12-month change in mean number of pills per day. Results of a previous similar intervention $^{12}$ showed that a prediabetic population decreased their medications' cost of $€ 75 \pm 100$ at 6 months. Using medications' cost as the main outcome and with the assumption that T2D patients will undergo similar benefits at 1 year, we calculated that a sample of 27 participants allows a statistical power $>80 \%$ with an $\alpha$ level $<5 \%$, correlation coefficient at 0.5 (due to paired context), allowing a dropout rate of $20 \%$. Changes over time were tested by a one-way ANOVA with repeated measures, with the use of Bonferroni post hoc test. We further calculated the global tendency over time (over the 1-year intervention programme). Correlation matrices between T2D patients medication cost and various clinical and biological parameters were constructed using Pearson or Spearman test, according to statistical distribution. To minimise the probability of false positives when numerous correlations are calculated, the independent 
associations of each parameter with medication cost were further assessed using a multivariable negative binomial generalised estimating equations (GEE) model. Indeed, the GEE approach allowed estimating the population average parameter; taking into account the clustering of participants, and applying the latter aspect in a working correlation matrix in the model. When the data are overdispersed (eg, for cost of routine medication), using negative binomial distribution is an appropriate alternative. We described our results calculating the regression coefficient and 95\% CI for each dependent variable on medication cost. Generalised linear mixed models (GLMM) with a $\log$ link function were performed to compare the number of participants depending on their characteristics and their routine medication cost. To study the parameters influencing the highest routine cost medications, this outcome was categorised in four modalities based on its statistical distribution (quartiles) and its clinical relevance. The descriptive characteristics of those who dropped out of the programme were also summarised. We also performed a descriptive statistical analysis for participants who dropped out to compare their characteristics with those who completed the programme. Significance was set at the $p<0.05$ level.

\section{RESULTS}

\section{Participants}

Twenty-nine participants (13 men, 16 women, aged 59.3 \pm 5.1 years, $93.6 \pm 14.1 \mathrm{~kg}$, body mass index $34.5 \pm 3.7 \mathrm{~kg} /$ $\mathrm{m}^{2}$ ) with T2D were recruited into this 1-year study starting with a 3-week residential programme. Three T2D patients were not taking medication for their diabetes. Among participants, $83 \%$ were taking blood pressure medications and $66 \%$ were taking lipid-lowering drugs (table 1). Baseline analyses resulted in mean blood values of $6.6 \pm 1.9 \mathrm{mmol} / \mathrm{L}$ for glucose and $7.0 \pm 0.8 \%$ for $\mathrm{HbAlc}$, as well as $142.4 \pm 11.5 \mathrm{~mm} \mathrm{Hg}$ for systolic and $84.7 \pm 8.7 \mathrm{~mm} \mathrm{Hg}$ for diastolic blood pressure. One participant left the study during the 3-week residential programme. Eighty-three per cent completed the whole intervention (figure 1). Baseline characteristics and cardiovascular risk profiles did not differ between those

Table 1 Profile of routine medication by class and change at 1 year

\begin{tabular}{|c|c|c|c|c|}
\hline & \multirow[b]{2}{*}{ Baseline $(n=29)$} & \multicolumn{3}{|c|}{ At 1 year } \\
\hline & & Stop & Decrease & Increase \\
\hline \multicolumn{5}{|c|}{ Routine medication-number of patients treated for: } \\
\hline Diabetes & 26 & 4 & 1 & 1 \\
\hline Blood pressure & 24 & 4 & 1 & 1 \\
\hline Lipid-lowering & 19 & 1 & - & - \\
\hline Analgesic & 1 & - & - & - \\
\hline Other & 14 & 3 & - & 3 \\
\hline ALL & 29 & 12 & 2 & 5 \\
\hline \multicolumn{5}{|c|}{ Routine medication-number of medication treating for: } \\
\hline Diabetes & 36 & 4 & 1 & 1 \\
\hline Biguanides & 20 & 3 & 1 & - \\
\hline Sulfamides & 8 & - & - & - \\
\hline Incretins & 1 & - & - & - \\
\hline Glitazones & 2 & 1 & - & - \\
\hline Glinides & 1 & - & - & 1 \\
\hline Others & 4 & - & - & - \\
\hline Insulin (exclusion criteria) & - & - & - & - \\
\hline Blood pressure & 42 & 5 & 1 & 3 \\
\hline$\beta$-Blockers & 4 & - & - & 1 \\
\hline ACE inhibitors & 5 & - & 1 & - \\
\hline Angiotensin II receptor antagonists & 13 & 2 & - & - \\
\hline Loop diuretics & 1 & 1 & - & 1 \\
\hline Thiazidic diuretics & 9 & - & - & - \\
\hline Potassium-sparing diuretics & 5 & - & - & 1 \\
\hline Calcium blockers and central agents & 5 & 2 & - & - \\
\hline Lipid-lowering & 20 & 1 & - & - \\
\hline Statins & 13 & 1 & - & - \\
\hline Fibrates & 6 & - & - & - \\
\hline Others & 1 & - & - & - \\
\hline Analgesic & 1 & - & - & - \\
\hline Others & 41 & 7 & - & 4 \\
\hline ALL & 140 & 17 & 2 & 8 \\
\hline
\end{tabular}


Table 2 One-year follow-up of outcomes in type 2 diabetes patients

\begin{tabular}{|c|c|c|c|c|c|c|}
\hline & Day 0 & Day 20 & Month 3 & Month 6 & Month 12 & $\begin{array}{l}\text { Global tendency } \\
\text { over time } \\
\text { p Value }\end{array}$ \\
\hline Weight, $\mathrm{cm}$ & $91.1 \pm 13.5$ & $86.4 \pm 12.4^{\star \star \star}$ & $85.0 \pm 12.1^{\star \star \star}+\dagger \dagger$ & $86.5 \pm 13.5^{\star \star \star}$ & $87.2 \pm 12.9^{\star \star}$ & $<0.001$ \\
\hline Waist circumference, $\mathrm{cm}$ & $105.0 \pm 10.4$ & $100.0 \pm 9.3^{\star \star \star}$ & $97.4 \pm 8.3^{\star \star \star}+\dagger$ & $98.5 \pm 9.2^{\star \star \star}$ & $98.2 \pm 9.2^{\star \star \star}$ & $<0.001$ \\
\hline Central fat, $\mathrm{g}$ & $3250.7 \pm 760.4$ & $2813.0 \pm 625.6^{\star \star \star}$ & 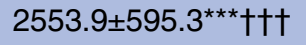 & $2631.1 \pm 807.0^{\star \star \star} \ddagger$ & $2776.4 \pm 712.3^{\star \star \star}$ & $<0.001$ \\
\hline Mean blood pressure, $\mathrm{mm} \mathrm{Hg}$ & $103.9 \pm 8.0$ & $96.3 \pm 8.8^{\star \star \star}$ & $102.3 \pm 6.4 \uparrow \dagger \dagger$ & $104.4 \pm 8.7 \dagger \dagger \dagger$ & $104.7 \pm 9.8 \dagger \dagger \dagger$ & 0.015 \\
\hline Systolic blood pressure, $\mathrm{mm} \mathrm{Hg}$ & $142.4 \pm 11.5$ & $133.4 \pm 9.7^{\star \star \star}$ & $138.8 \pm 8.2^{*} \dagger \dagger$ & $140.5 \pm 11.7 \ddagger$ & $140.9 \pm 12.9 \S \S$ & 0.431 \\
\hline Diastolic blood pressure, $\mathrm{mm} \mathrm{Hg}$ & $84.7 \pm 8.7$ & $77.8 \pm 9.5^{\star \star \star}$ & $84.1 \pm 8.4 \uparrow \dagger \dagger$ & $86.4 \pm 8.8 \ddagger \ddagger \ddagger$ & $86.6 \pm 10.2 \S \S \S$ & 0.003 \\
\hline Pulse pressure, $\mathrm{mm} \mathrm{Hg}$ & $57.7 \pm 11.8$ & $55.6 \pm 7.9$ & $54.7 \pm 11.2$ & $54.1 \pm 9.9$ & $54.3 \pm 11.4$ & 0.074 \\
\hline $\mathrm{HbA} 1 \mathrm{c}, \%$ & $7.0 \pm 0.8$ & $6.6 \pm 0.8^{\star \star \star}$ & $6.3 \pm 0.7^{\star \star \star} \dagger \dagger$ & $6.2 \pm 0.7^{\star \star \star} \neq \ddagger$ & $6.4 \pm 0.8^{\star \star \star}$ & $<0.001$ \\
\hline Blood glucose levels, mmol/L & $6.6 \pm 1.9$ & $5.2 \pm 1.1^{\star \star \star}$ & $5.1 \pm 1.1^{\star \star \star}$ & $5.4 \pm 1.3^{\star \star}$ & $5.4 \pm 1.1^{\star \star}$ & 0.002 \\
\hline Insulin, mIU/L & $41.1 \pm 13.2$ & $34.8 \pm 15.1^{\star \star}$ & $44.7 \pm 16.6+\dagger$ & $52.4 \pm 18.1^{\star \star}$ 㧊 & $42.6 \pm 16.0 \S$ & 0.015 \\
\hline Cholesterol, mmol/L & $5.2 \pm 1.0$ & $4.3 \pm 1.1^{\star * *}$ & $5.1 \pm 1.2 \dagger \dagger \dagger$ & $5.0 \pm 0.6 \ddagger \ddagger \ddagger$ & $5.1 \pm 0.7 \S \S \S$ & 0.235 \\
\hline Triglycaerides, $\mathrm{mmol} / \mathrm{L}$ & $2.0 \pm 1.1$ & $1.4 \pm 0.3^{\star \star \star}$ & $1.7 \pm 0.9^{\star}$ & $1.7 \pm 1.0^{*}$ & $1.9 \pm 1.3 \S$ & 0.554 \\
\hline High-density lipoprotein (HDL), mmol/L & $1.2 \pm 0.2$ & $1.1 \pm 0.2$ & $1.3 \pm 0.2^{* *}+\dagger$ & $1.3 \pm 0.3^{\star \star} \neq \ddagger$ & $1.3 \pm 0.3^{* * \star} \S \S \S$ & $<0.001$ \\
\hline Low-density lipoprotein (LDL), mmol/L & $3.3 \pm 1.2$ & $2.5 \pm 1.1^{\star \star \star}$ & $3.1 \pm 1.1 \mathrm{t \dagger \dagger}$ & $3.0 \pm 0.9 \pm \pm \ddagger$ & $3.0 \pm 0.7 \S \S$ & 0.995 \\
\hline Creatine, $\mu \mathrm{mol} / \mathrm{L}$ & $71.9 \pm 20.7$ & $76.0 \pm 25.8^{*}$ & $75.1 \pm 21.8$ & $73.1 \pm 20.6$ & $75.8 \pm 19.9$ & 0.300 \\
\hline hs $C$ reactive protein (CRP), $\mathrm{mg} / \mathrm{L}$ & $4.9 \pm 4.6$ & $3.3 \pm 3.2^{*}$ & $5.4 \pm 7.1$ & $3.0 \pm 2.2^{\star \star}$ & $2.8 \pm 2.5^{\star \star}$ & 0.060 \\
\hline$I L-6, p g / m L$ & $4.2 \pm 4.5$ & $2.9 \pm 2.8$ & $2.6 \pm 3.0^{* *}$ & $2.3 \pm 2.1^{\star \star}$ & $1.9 \pm 1.1^{\star \star} \S$ & $<0.001$ \\
\hline NTproBNP, pg/mL & $27.3 \pm 73.5$ & $40.0 \pm 61.0$ & $41.2 \pm 57.8$ & $25.2 \pm 51.8$ & $24.8 \pm 36.4$ & 0.420 \\
\hline VEGF, $p g / m L$ & $247.7 \pm 316.8$ & $235.7 \pm 298.6$ & $179.7 \pm 99.2$ & $173.5 \pm 245.5$ & $197.5 \pm 258.5$ & 0.217 \\
\hline TNF, pg/mL & $11.4 \pm 9.3$ & $9.3 \pm 4.4$ & $5.1 \pm 3.1^{\star \star}+\dagger \dagger$ & $5.7 \pm 2.4^{\star \star} \ddagger \ddagger \ddagger$ & $5.9 \pm 3.0 * \S \S \S$ & $<0.001$ \\
\hline Six minutes' walk test, $m$ & $561.7 \pm 74.1$ & $612.1 \pm 64.1^{* * *}$ & $638.3 \pm 79.4^{* \star \star}+\dagger$ & $644.8 \pm 75.9^{* \star \star} \neq \ddagger$ & $638.8 \pm 60.2^{* \star \star} \S$ & $<0.001$ \\
\hline Strength max, $\mathrm{kg}$ & $399.3 \pm 210.1$ & $464.0 \pm 242.5^{\star \star}$ & $584.6 \pm 310.1^{\star \star \star} \dagger \dagger$ & $597.9 \pm 300.8^{\star \star \star} \ddagger \ddagger$ & $592.8 \pm 320.2^{\star \star}$ & $<0.001$ \\
\hline \multicolumn{7}{|l|}{ Routine medications: } \\
\hline Total cost/year, $€$ & $1352.6 \pm 1764.8$ & $1325.9 \pm 1775.9^{\star \star}$ & $1305.3 \pm 1785.9^{\star *}$ & $1307.7 \pm 1762.9$ & $1239.5 \pm 1660.3$ & 0.135 \\
\hline Routine pills, number & $7.6 \pm 3.1$ & $6.9 \pm 3.4^{\star \star \star}$ & $6.6 \pm 3.5^{\star * \star} \dagger$ & $6.5 \pm 3.4^{\star \star \star}$ & $6.2 \pm 3.2^{\star \star \star}$ & $<0.001$ \\
\hline \multicolumn{7}{|c|}{ Cost in euros/year of medications treating for: } \\
\hline Diabetes & $212.6 \pm 35.8$ & $188.8 \pm 36.2^{*}$ & $196.0 \pm 52.9$ & $143.1 \pm 43.7^{*}$ & $135.1 \pm 43.9^{*}$ & 0.014 \\
\hline Blood pressure & $270.4 \pm 37.7$ & $263.1 \pm 37.4$ & $242.7 \pm 39.7$ & $205.2 \pm 37.2^{*} \dagger$ & $215.0 \pm 41.1$ & 0.004 \\
\hline Lipid-lowering & $146.4 \pm 36.0$ & $146.4 \pm 36.0$ & $130.8 \pm 36.4$ & $145.6 \pm 38.0$ & $122.7 \pm 37.0$ & 0.063 \\
\hline Other & $677.3 \pm 282.3$ & $677.3 \pm 282.3$ & $671.5 \pm 282.7$ & $685.4 \pm 282.5$ & $613.8 \pm 270.6$ & 0.069 \\
\hline
\end{tabular}

Significant $\mathrm{p}$ Values are written in bold.

Variables written in italic did not follow a Gaussian distribution.

${ }^{* * *}: p<0.001$ versus D0; ${ }^{* *}: p<0.01$ versus $D 0 ;{ }^{*}: p<0.05$ versus D0.

$\dagger+t: p<0.001$ versus D20; $\dagger+: p<0.01$ versus $D 20 ; t: p<0.05$ versus D20 (D0 excluded).

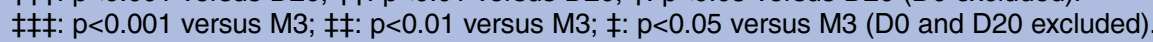

$\S \S \S: p<0.001$ versus M6; $\S \S: p<0.01$ versus M6; $\S$ : $p<0.05$ versus M6 (D0, D20 and M3 excluded).

IL-6, interleukin 6; NT-proBNP, N-terminal pro-brain natriuretic peptide; (TNF)- $\alpha$, tumor necrosis Factor - $\alpha$; VEGF, vascular endothelial growth factor. 
who completed the programme and the two participants who withdrew. At 1 year, decreases of $22.0 \pm 0.7 \%$ for glucose, $9.0 \pm 0.1 \%$ for $\mathrm{HbAlc}$, and $1.0 \pm 10.1 \%$ for systolic and $2.0 \pm 0.2 \%$ for diastolic blood pressure were observed. Results from anthropometric data showed a decrease of $3.8 \pm 1.4 \%$ for weight, $7.0 \pm 0.1 \%$ for waist circumference and $150.0 \pm 0.1 \%$ for central fat. Blood lipid profile, inflammation and fitness test followed similar improvements (table 2). The mean compliance scores for diet and exercise during the at-home follow-up significantly decreased over time, from $56.1 \pm 28.2 \%$ between D20 and M3, $48.5 \pm 27.3 \%$ between M3 and M6 to $37.5 \pm 22.1 \%$ between M6 and M12 $\quad(\mathrm{p}<0.001$ for the global tendency).

\section{Primary outcomes: medications}

The 29 patients were followed by 29 different general practitioners. General practitioners continued their usual practice for T2D management and cardiovascular risks. They were not in contact with investigators. Results of basic blood biology (glycaemia, lipid profile) were given to participants. Participants were never advised to see their general practitioner.

At D0, patients consumed 7.56 \pm 3.08 tablets/day, that is, $2758 \pm 1124$ tablets/year, at a mean routine medication cost/patient/year of $€ 1352.6 \pm 1764.8$ (figure 2). At 1 year, 14 patients out of $26(54 \%)$ ceased or decreased their medications, whereas only $5(19 \%)$ increased or introduced new drugs $\left(\chi^{2}=6.3, p=0.02\right)$. Similarly, 19 medications were ceased or decreased out of $140(14 \%)$ whereas only $8(6 \%)$ medications were increased or introduced $\left(\chi^{2}=5.0, p=0.02\right)$ (table 1$)$. The number of routine pills significantly decreased at each measurement time during the 1-year follow-up. The number of

\section{Number of routine pills per day}

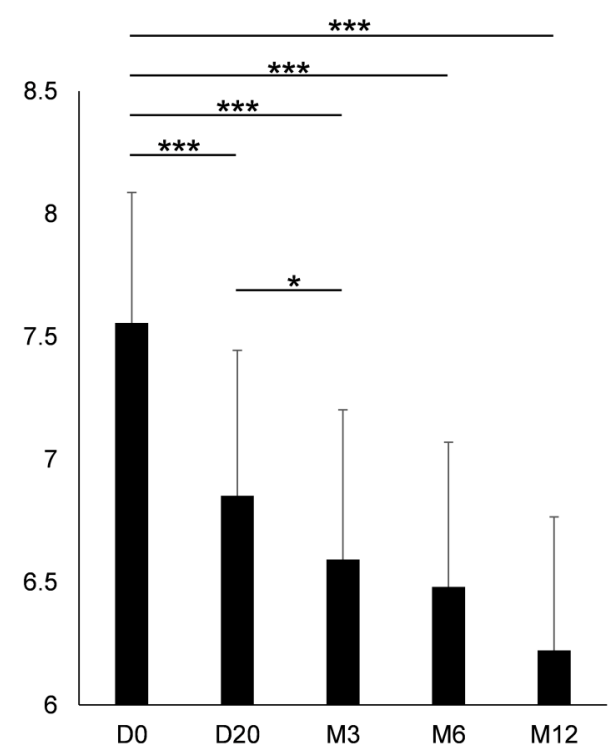

pills per day decreased by $1.3 \pm 0.3$ at 12 months $(p<0.001)$ (figure 2). For the total cost of routine medication, the benefit was only significant until 3 months (figure 2). Although not significant $(p=0.135)$ for the total cost, the decrease in total cost could be estimated around $€ 110 /$ patient/year at the end of the intervention. The global tendency over the whole 1-year intervention programme was a significant decrease of around $€ 60$ in cost of medications treating for T2D $(\mathrm{p}=0.014)$, and a significant decrease of $€ 50$ in cost of medications treating for high blood pressure $(\mathrm{p}=0.004)$ (figure 3 ). The global tendency was close to significance for the $€ 20$ decrease in cost of lipid-lowering drugs $(\mathrm{p}=0.063)$ and for the $€ 60$ decrease in cost of other medications ( $\mathrm{p}=0.069)$ (figure 3).

\section{Multivariable analyses}

Changes over time in routine medication costs and the impact of covariates on these changes were separately modelled using a multivariable GEE modelling that also accounted for variation in the correlation between the repeated measurements (figure 4 ). In the multivariable model, we controlled for weight, central fat, blood pressure, lipid profile, glucose metabolism, inflammation and fitness test results. Glycaemia and $\mathrm{HbAlc}$ were the only parameters independently associated with the cost of routine medication. The regression coefficients on the cost of routine medication were 0.507 (95\% CI 0.056 to $0.959, \mathrm{p}=0.027)$ for HbAlc and $0.156(95 \% \mathrm{CI}-0.010$ to $0.322, \mathrm{p}=0.06$ ) for blood glucose levels. Finally, higher glycaemic control was associated with lower routine medication costs (figure 4). Using GLMM, the number of diabetes participants with high levels of HbAlc doubled in the high (last quartile) part of routine cost

\section{Annual cost of all medications}

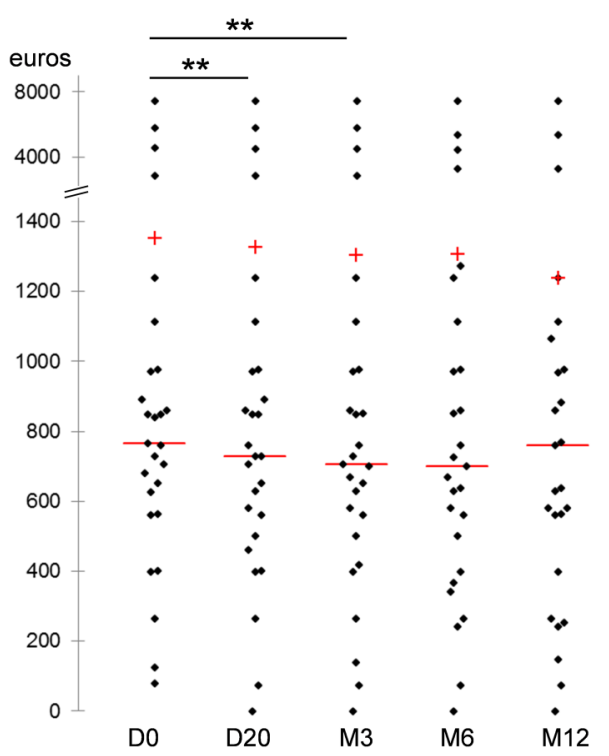

Figure 2 Number of routine pills per day (mean \pm SE) and annual cost of all medications (scattergram). +, mean; -, median; ${ }^{*} \mathrm{p}<0.05 ;{ }^{* *} \mathrm{p}<0.01 ;{ }^{* * *} \mathrm{p}<0.001$. 
Annual cost of medications for type 2 diabetes

(global tendency over time $\mathrm{p}=0.014$ )

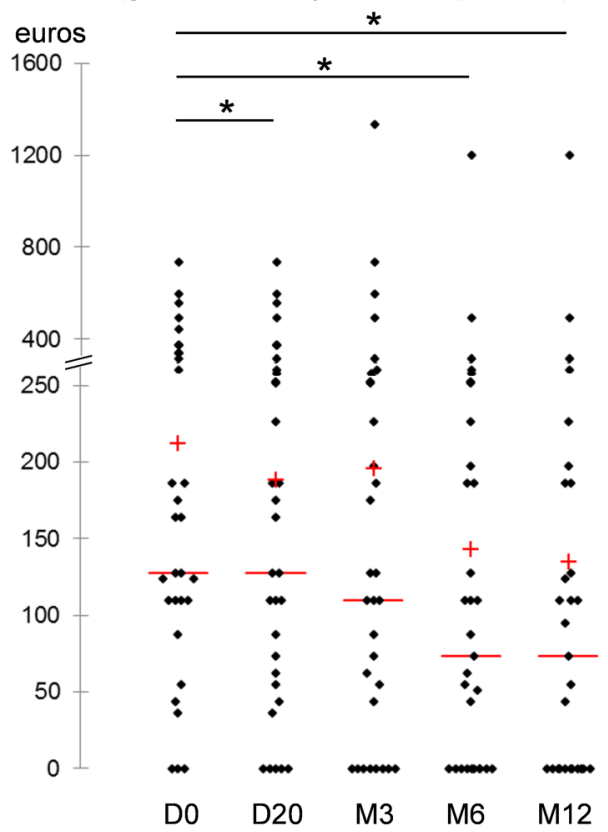

Annual cost of lipid lowering drugs (global tendency over time $p=0.063$ )

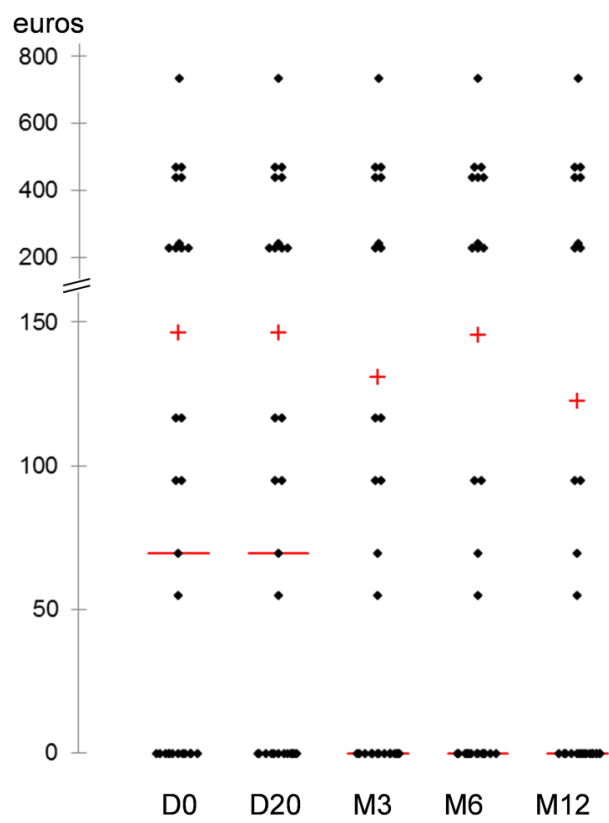

Annual cost of medications

for high blood pressure

(global tendency over time $p=0.004$ )

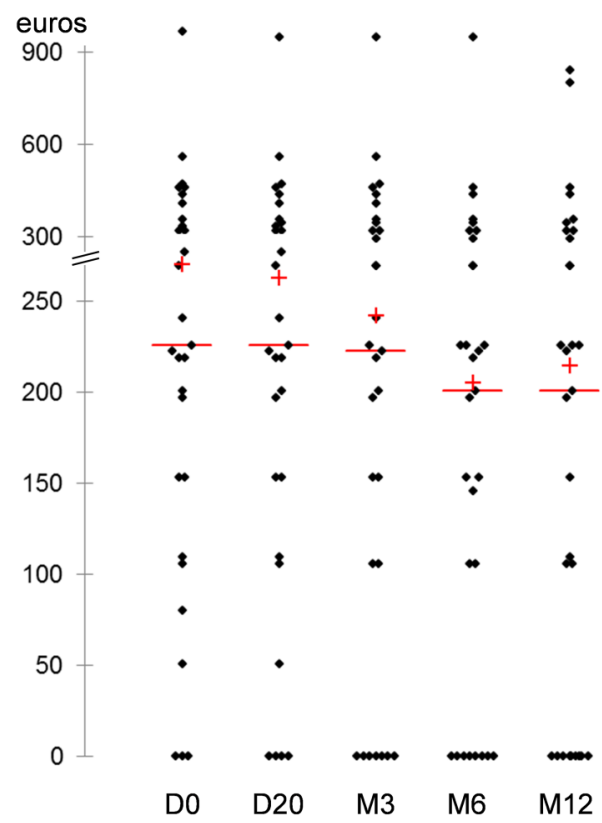

Annual cost of other medications

(global tendency over time $p=0.069$ )

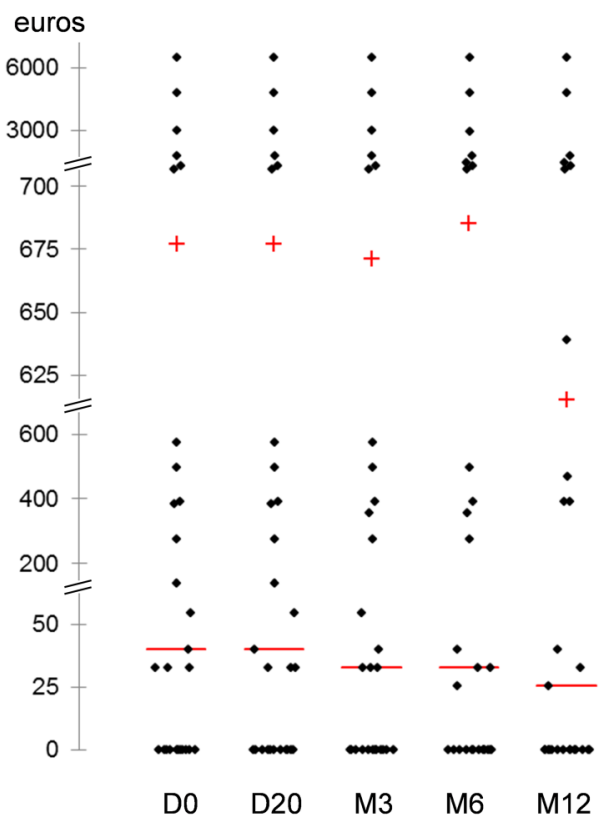

Figure 3 Annual cost of medications for type 2 diabetes, high blood pressure, dyslipidemia and other medications (scattergrams). +, mean; -, median; ${ }^{\star} p<0.05 ;{ }^{* \star} p<0.01 ;{ }^{\star \star \star} p<0.001$.

medication: $66 \%$ of T2D patients with an $\mathrm{HbA1c}>6.5 \%$ versus $33 \%$ with an HbA1c $<6.5 \%$ ( $\mathrm{p}=0.037)$. However, we did not find associations between routine medication cost and clinical parameters (age, sex, weight, central fat, blood pressure, blood lipids, inflammation or fitness test).

\section{DISCUSSION}

\section{Principal findings}

The major finding showed that the intervention decreased the number of medications taken by T2D patients, which represented a reduction around $€ 110$ per participant in the annual cost of medication. The 


\begin{tabular}{|c|c|c|c|c|c|}
\hline Variables & 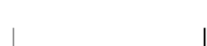 & & Coefficient & IC $95 \%$ & p-value \\
\hline Age, years & - & & -0.012 & $(-0.093,0.070)$ & 0.778 \\
\hline Male gender, female as reference & $\longleftarrow$ & & -0.174 & $(-1.224,0.876)$ & 0.746 \\
\hline Weight, kg & & p & 0.03 & $(-0.015,0.076)$ & 0.191 \\
\hline Central fat, $\mathrm{g}$ & & & 0.000 & $(-0.001,0.000)$ & 0.585 \\
\hline Systolic Blood Pressure, $\mathrm{mmHg}$ & & & 0.005 & $(-0.015,0.025)$ & 0.638 \\
\hline Diastolic Blood Pressure, $\mathrm{mmHg}$ & & & -0.007 & $(-0.051,0.035)$ & 0.735 \\
\hline HbA1c* $\%$ & & - & 0.507 & $(0.056,0.959)$ & 0.027 \\
\hline Total cholesterol, $\mathrm{mmol} / \mathrm{l}$ & $\leftarrow$ & & 0.509 & $(-2.620,3.638)$ & 0.750 \\
\hline Triglycerides, $\mathrm{mmol} / \mathrm{l}$ & $\leftarrow$ & & -0.139 & $(-1.267,0.988)$ & 0.809 \\
\hline $\mathrm{HDL}, \mathrm{mmol} / \mathrm{l}$ & 4 & & -0.599 & $(-3.891,2.692)$ & 0.721 \\
\hline LDL, mmol/l & $\leftarrow \infty$ & & -0.705 & $(-3.871,2.462)$ & 0.663 \\
\hline CRPus, UI/I & $\longrightarrow$ & - & -0.023 & $(-0.540,0.008)$ & 0.146 \\
\hline IL6, $\mu \mathrm{g} / \mathrm{I}$ & & & -0.015 & $(-0.049,0.079)$ & 0.636 \\
\hline NTproBNP, $\mu g / l$ & & & -0.002 & $(-0.007,0.004)$ & 0.538 \\
\hline TNF, $\mu g / l$ & & & -0.009 & $(-0.062,0.043)$ & 0.732 \\
\hline VEGF, $\mu \mathrm{g} / \mathrm{l}$ & & & 0.000 & $(-0.001,0.001)$ & 0.882 \\
\hline Six Minutes' walk test, metres & & 0 & 0.001 & $(-0.003,0.005)$ & 0.699 \\
\hline Strength Max, kg & & 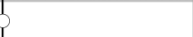 & 0.001 & $(-0.001,0.002)$ & 0.314 \\
\hline & -1 & & & & \\
\hline
\end{tabular}

Figure 4 Relationships between cost of routine medication and clinical and biological parameters (generalised estimating equations multivariable analyses). ${ }^{*}$ With blood glucose levels: $0.156(-0.010-0.322), p=0.066$; other results were similar.

independent factor explaining decreased medication was better glycaemic control: the regression coefficients on the cost of routine medication were 0.507 (95\% CI 0.056 to $0.959, \mathrm{p}=0.027$ ) for HbAlc and 0.156 (95\% CI -0.010 to $0.322, \mathrm{p}=0.066$ ) for blood glucose levels.

\section{Impact of a lifestyle management programme on T2D medication cost}

A simulation model accounting for all costs to the US healthcare system suggested that within 25 years, lifestyle intervention programmes would prevent or delay about 885000 cases of T2D, representing savings of $\$ 5.7$ billion nationwide. ${ }^{16}$ Despite the limitations of the current study precluding generalisability, the intervention decreased the annual cost by $€ 110$ per participant. Taking into account the global pandemic of T2D, ${ }^{17} 18$ lifestyle intervention would represent non-negligible fiscal savings. A previous study showed markedly decreased costs to the annual cost of individuals who had a more severe T2D diagnosis (HbAlc 8\%, with complications) when they were exposed to a 'realistic' training protocol. ${ }^{19}$ We demonstrated that we could generate a similar magnitude of cost reduction with healthier T2D participants (HbA1c at 7\%, without complications). Diabetes prevention programmes may achieve even greater health and economic gains if directed at younger people. ${ }^{16}$ Our study was restricted to 5070 years old participants and therefore a larger study on younger T2D patients should be implemented. As previously suggested, ${ }^{20}$ the benefits associated with selfmanagement education and lifestyle modification for people with T2D are positive in terms of health benefits, and outweigh the costs associated with the intervention. In our study, the amount reimbursed from the French national healthcare insurance for the cost of the residential programme seemed to be approximately equivalent to the savings in annual routine medication costs.

\section{Impact of glycaemia on health and cost}

The improvement in glycaemic control following our residential programme aligns with the findings from a recent meta-analysis demonstrating impacts of physical activity recommendations associated with an appropriate diet. ${ }^{21}$ We confirmed the mean HbA1c decrease of $0.6 \%$ previously demonstrated in a meta-analysis including mainly studies with a 8-week follow-up. ${ }^{22}$ However, benefits were still significant at 1 year. Improved glycaemic control was shown to decrease routine medications. ${ }^{36718}$ Such lifestyle interventions aiming to control for glycaemic metabolism must involve broad resources. To establish partnerships with health-related institutions is a major key issue for lifestyle behavioural changes and its longterm inclusion in the daily lives of individuals with T2D. It is important to promote collaborations between health professionals and institutions to raise awareness, train organisers and discuss management objectives. ${ }^{23}$ Although a cost-sparing effect of exercise in T2D has been previously studied, ${ }^{19}$ the current study was needed because the treatment of diabetes has been markedly modified with the removal of glitazones ${ }^{24}$ and the appearance of dipeptidyl peptidase-4 (DPP4) inhibitors and glucagon-like peptide-1 (GLP1) agonists, ${ }^{25}$ generating higher medications costs than were likely to be incurred at the time of the previous study. ${ }^{26}$ Few participants in our study were being administered new drugs and their costs were not modified. However, despite limitations precluding generalisability, our intensive exercise protocol showed significant long-term health benefits and cost reduction in healthier T2D than previously 
reported. ${ }^{19}$ We demonstrated for the first time that those cost improvements were mediated by a better glycaemic control and not by weight loss or other variables. ${ }^{27} 28$

\section{Strengths and limitations}

The strengths of our study are a run-in design with community-based long-term intervention; we evaluated the cost of global routine medication in T2D patients; and we used an appropriate model to assess the independent associations of routine medication costs with only glycaemic control, taking into account variations of correlations over time. Innovation also lies in training volumes (15-20 hours/week) that have seldom been investigated in obesity intervention over 12 months.

The main limitations of this study are a small sample size of T2D patients and the absence of a randomised controlled trial design. A group without physical activity could have provided opportunities to distinguish the effects of physical activity from the diet. Owing to the lack of a control group without intervention, we cannot assess the influence of putative side effects of drugs on cessation or dose decrease of medication. However, those long-term medication were initiated several years before our study and most often side effects appear at the introduction of a medication. Moreover, a physician from our team had a private interview with all patients at each measurement time to assess the rationale for any changes in medications. The causes of decreased doses of medication treating for diabetes were decreases in HbA1c and some hypoglycaemia (even if not common with biguanides; the reason why general practitioners did not change sulfamides doses is unknown); the cause for decreased doses of medication prescribed for high blood pressure diabetes was lower blood pressure. We did not repeat the maximal exercise tolerance test due to limited time available for participants during follow-up. However, the $6 \mathrm{~min}$ walk test is an accurate tool versus maximal oxygen uptake in evaluating endurance performance. ${ }^{29}$ Although we previously demonstrated a link between compliance to new lifestyle and health benefits, ${ }^{30} 31$ the limited sample size of this study did not retrieve significant relationships. Implementing our intervention into routine healthcare is costly and our high volume training protocol ( 15 hours/week) may prove difficult to comply with in usual practice. The implementation of this programme would require substantial financial resources; thus, budgetary constraints could limit the number of people to whom the lifestyle intervention could be delivered. Moreover, there seems to be a tendency to steady state and even a mild reversal of the global effect at 12 months for some variables, which could be due to a relative decrease in training volume reported during the follow-up. Difficulty in maintaining the long-term high volume of training could be one of the pitfalls of such interventions and may require a revised prescription of exercise at regular intervals. The question of the modalities of exercise training during follow-up for a better compliance and health benefits should generate new hypotheses. Eventually, despite benefits in terms of cost of routine medications for patients and French national healthcare insurance, the cost-effectiveness impact of our intervention on overall medical cost in terms of complications of T2D, number of hospitalisations and length of hospital stays would have required a prolonged follow-up over several years in a large sample size. Even if such studies are specific of a national health system, our results may be largely generalisable to other situations in various countries.

\section{CONCLUSION}

In a small sample of T2D patients, reducing the longterm cost of global routine medication and number of pills could be effective following a 3-week lifestyle residential combining high exercise volume, restrictive diet and education. The only factor correlated with this decreased medication cost was the glycaemic control in the absence of weight change. Implementing such a programme could be an efficient use of healthcare resource. To maintain this lifestyle education in long term may need the support of health related institutions specialised in T2D patients' management.

\section{Author affiliations}

${ }^{1}$ Université Clermont Auvergne, CNRS, LaPSCo, Physiological and psychosocial stress, CHU Clermont-Ferrand, Preventive and Occupational Medicine, Sports Medicine, F-63000 Clermont-Ferrand, France

2Université d'Avignon, LaPEC EA4278, Laboratory of Cardiovascular PharmEcology, F-84000 Avignon, France

${ }^{3}$ Université Clermont Auvergne, Laboratory of Metabolic Adaptations to Exercise in Physiological and Pathological conditions (AME2P), F-63000 Clermont-Ferrand, France

${ }^{4}$ Australian Catholic University, Faculty of Health, School of Exercise Science, Melbourne, Victoria 3065, Australia

${ }^{5} \mathrm{CHU}$ Clermont-Ferrand, the Clinical Research and Innovation Direction, F-63000 Clermont-Ferrand, France

${ }^{6}$ Université Clermont Auvergne, INRA, UNH, Unité de Nutrition Humaine, CRNH Auvergne, CHU Clermont-Ferrand, Sports Medicine, F-63000 ClermontFerrand, France

${ }^{7}$ Université Clermont Auvergne, CNRS, LaPSCo, Physiological and psychosocial stress, CHU Clermont-Ferrand, Preventive and Occupational Medicine, WittyFit, F-63000 Clermont-Ferrand, France

Acknowledgements This work was supported by Blaise Pascal UniversityLaboratory of Metabolic Adaptations to Exercise under Physiological and Pathological Conditions and by the thermal baths of Chatel-Guyon and the Omental Thermalia, Chatelguyon, France.

Contributors FD has participated as a PhD student and main investigator. $\mathrm{FD}, \mathrm{BL}, \mathrm{DC}, \mathrm{PO}, \mathrm{GW}$ and $\mathrm{AV}$ contributed to the conception of the protocol. FD recruited all patients. MD and FD performed maximal exercise testing. FD performed aliquoting of blood samples. RC was responsible for the residential programme. BL supervised daily diet and managed physical activity. BP and FD conducted the statistical analysis. CL and FD drafted the manuscript. GN and $B P$ revised the manuscript. All authors critically reviewed the scientific content and approved the final version to be published. CL and FD take full responsibility for the work as a whole.

Funding The study was supported by the Fondation Coeur et Artères 59200 Loos, France, grant number is FCA $N^{\circ} 07 \mathrm{~T} 2$. http://www.fondacoeur.com.

Competing interests None declared. 
Patient consent Obtained

Ethics approval The study was approved by university hospital ethics committees from St Etienne, France.

Provenance and peer review Not commissioned; externally peer reviewed.

Data sharing statement No additional data are available.

Open Access This is an Open Access article distributed in accordance with the Creative Commons Attribution Non Commercial (CC BY-NC 4.0) license, which permits others to distribute, remix, adapt, build upon this work noncommercially, and license their derivative works on different terms, provided the original work is properly cited and the use is non-commercial. See: http:// creativecommons.org/licenses/by-nc/4.0/

\section{REFERENCES}

1. Association AD. Diabetes statistics. November 3, 2004.

2. Chiasson JL, Le Lorier J. Glycaemic control, cardiovascular disease, and mortality in type 2 diabetes. Lancet 2014;384:1906-7.

3. Boyle JP, Thompson TJ, Gregg EW, et al. Projection of the year 2050 burden of diabetes in the US adult population: dynamic modeling of incidence, mortality, and prediabetes prevalence. Popul Health Metr 2010;8:29.

4. Dobson R, Carter K, Cutfield R, et al. Diabetes text-message self-management support program (sms4bg): a pilot study. JMIR Mhealth Uhealth 2015;3:e32.

5. American Diabetes Association. Economic costs of diabetes in the U.S. in 2012. Diabetes Care 2013;36:1033-46.

6. Federation ID. Diabetes Atlas Brussels, Belgium: international diabetes federation 2006

7. Wang W, McGreevey WP, Fu C, et al. Type 2 diabetes mellitus in China: a preventable economic burden. Am J Manag Care 2009:15:593-601.

8. Standards of medical care in diabetes-2015: summary of revisions Diabetes Care 2015;38:dc15-S003.

9. Alberti KG, Zimmet P, Shaw J. The metabolic syndrome-a new worldwide definition. Lancet 2005;366:1059-62.

10. Crendal E, Walther $G$, Dutheil F, et al. Left ventricular myocardial dyssynchrony is already present in nondiabetic patients with metabolic syndrome. Can J Cardiol 2013;30:320-4.

11. Black AE, Coward WA, Cole TJ, et al. Human energy expenditure in affluent societies: an analysis of 574 doubly-labelled water measurements. Eur J Clin Nutr 1996;50:72-92.

12. Dutheil F, Lesourd B, Courteix D, et al. Blood lipids and adipokines concentrations during a 6-month nutritional and physical activity intervention for metabolic syndrome treatment. Lipids Health Dis 2010;9:148.

13. Dutheil F, Lac G, Lesourd B, et al. Different modalities of exercise to reduce visceral fat mass and cardiovascular risk in metabolic syndrome: the resolve randomized trial. Int $J$ Cardiol 2013;168:3634-42

14. Kamel EG, McNeill G, Van Wijk MC. Usefulness of anthropometry and DXA in predicting intra-abdominal fat in obese men and women. Obes Res 2000;8:36-42.
15. ATS Committee on Proficiency Standards for Clinical Pulmonary Function Laboratories. ATS statement: guidelines for the six-minute walk test. Am J Respir Crit Care Med 2002;166:111-17.

16. Zhuo X, Zhang P, Gregg EW, et al. A nationwide community-based lifestyle program could delay or prevent type 2 diabetes cases and save $\$ 5.7$ billion in 25 years. Health Aff 2012;31:50-60.

17. Organisation WH. Diabetes action now: an initiative of the world health organisation and the international diabetes federation. International Diabetes Federation, 2004

18. Wing RR. Long-term effects of a lifestyle intervention on weight and cardiovascular risk factors in individuals with type 2 diabetes mellitus: four-year results of the look ahead trial. Arch Intern Med 2010;170:1566-75.

19. Brun JF, Bordenave S, Mercier J, et al. Cost-sparing effect of twice-weekly targeted endurance training in type 2 diabetics: a one-year controlled randomized trial. Diabetes Metab 2008;34:258-65.

20. Boren SA, Fitzner KA, Panhalkar PS, et al. Costs and benefits associated with diabetes education: a review of the literature. Diabetes Educ 2009;35:72-96.

21. Umpierre D, Ribeiro PA, Kramer CK, et al. Physical activity advice only or structured exercise training and association with $\mathrm{HbA} 1 \mathrm{c}$ levels in type 2 diabetes: a systematic review and meta-analysis. JAMA 2011;305:1790-9.

22. Thomas DE, Elliott EJ, Naughton GA. Exercise for type 2 diabetes mellitus. Cochrane Database Syst Rev 2006:CD002968.

23. Duclos M, Oppert JM, Verges B, et al. Physical activity and type 2 diabetes. Recommandations of the SFD (francophone diabetes society) diabetes and physical activity working group. Diabetes Metab 2013;39:205-16.

24. Aspinall SE, Zhao X, Good CB, et al. FDA warning and removal of rosiglitazone from VA national formulary. Am J Manag Care 2013;19:748-58.

25. Drucker DJ, Nauck MA. The incretin system: glucagon-like peptide-1 receptor agonists and dipeptidyl peptidase-4 inhibitors in type 2 diabetes. Lancet 2006;368:1696-705.

26. Halimi S. DPP-4 inhibitors and GLP-1 analogues: For whom? Which place for incretins in the management of type 2 diabetic patients? Diabetes Metab 2008;34(Suppl 2):S91-5.

27. Yi Y, Philips Z, Bergman G, et al. Economic models in type 2 diabetes. Curr Med Res Opin 2010;26:2105-18.

28. Picot J, Jones $\mathrm{J}$, Colquitt $\mathrm{JL}$, et al. Weight loss surgery for mild to moderate obesity: a systematic review and economic evaluation. Obes Surg 2012;22:1496-506.

29. Cataneo DC, Kobayasi S, Carvalho LR, et al. Accuracy of six minute walk test, stair test and spirometry using maximal oxygen uptake as gold standard. Acta Cirurgica Brasileira 2010:25:194-200.

30. Courteix D, Valente-Dos-Santos J, Ferry B, et al. Correction: Multilevel approach of a 1-year program of dietary and exercise interventions on bone mineral content and density in metabolic syndrome: the resolve randomized controlled trial. PLOS ONE 2015:10:e0140307.

31. Courteix D, Valente-Dos-Santos J, Ferry B, et al. Multilevel approach of a 1-year program of dietary and exercise interventions on bone mineral content and density in metabolic syndromethe resolve randomized controlled trial. PLOS ONE 2015;10: e0136491. 